\title{
An Analysis of Changes in Residential Energy \\ Consumption, 1973-1980
}

\author{
M. J. King \\ D. B. Belzer \\ J. M. Callaway \\ R. C. Adams
}

September 1982

Prepared for the U.S. Department of Energy under Contract DE-AC06-76RLO 1830

Pacific Northwest Laboratory

Operated for the U.S. Department of Energy by Battelle Memorial Institute 


\title{
DISCLAIMER
}

This report was prepared as an account of work sponsored by an agency of the United States Government. Neither the United States Government nor any agency thereof, nor any of their employees, makes any warranty, express or implied, or assumes any legal liability or responsibility for the accuracy, completeness, or usefulness of any information, apparatus, product, or process disclosed, or represents that its use would not infringe privately owned rights. Reference herein to any specific commercial product, process, or service by trade name, trademark, manufacturer, or otherwise, does not necessarily constitute or imply its endorsement, recommendation, or favoring by the United States Government or any agency thereof. The views and opinions of authors expressed herein do not necessarily state or reflect those of the United States Government or any agency thereof.

\author{
PACIFIC NORTHWEST LABORATORY \\ operated by \\ BATTELLE \\ for the \\ UNITED STATES DEPARTMENT OF ENERGY \\ under Contract DE-AC06-76RLO 1830
}

\begin{tabular}{|c|c|}
\hline \multicolumn{2}{|c|}{$\begin{array}{l}\text { Printed in the United States of America } \\
\text { Available from } \\
\text { National Technical Information Service } \\
\text { United States Department of Commerce } \\
5285 \text { Port Royal Road } \\
\text { Springfield, Virginia } 22151\end{array}$} \\
\hline \multicolumn{2}{|c|}{$\begin{array}{l}\text { NTIS Price Codes } \\
\text { Microfiche A01 }\end{array}$} \\
\hline \multicolumn{2}{|c|}{ Printed Copy } \\
\hline Pages & $\begin{array}{l}\text { Price } \\
\text { Codes }\end{array}$ \\
\hline $001-025$ & $\mathrm{~A} 02$ \\
\hline 026.050 & $\mathrm{AO3}$ \\
\hline $051 \cdot 075$ & $\mathrm{AO4}$ \\
\hline $076-100$ & A05 \\
\hline $101-125$ & $A 06$ \\
\hline $126-150$ & $A 07$ \\
\hline 151.175 & $A 08$ \\
\hline $176-200$ & $A 09$ \\
\hline 201.225 & A010 \\
\hline $226-250$ & A011 \\
\hline 251.275 & A012 \\
\hline $276-300$ & $A 013$ \\
\hline
\end{tabular}


AN ANALYSIS OF CHANGES IN

RESIDENTIAL ENERGY

CONSUMPTION, 1973-1980

M. J. King

D. B. Belzer

J. M. Callaway

R. C. Adams

September 1982

Prepared for

the U. S. Department of Energy

under Contract DE-AC06-76RLO 1830

Pacific Northwest Laboratory

Richland, Washington 99352 



\section{SUMMARY}

This report was prepared for the Office of Policy, Planning, and Analysis of the U.S. Department of Energy to assess the progress of energy conservation in the residential sector since the 1973-1974 Arab oil embargo. To accomplish this goal, Pacific Northwest Labratory (PNL) disaggregated the reduction in residential energy use per household since 1973 into six possible factors. The factors considered were: (1) building shell efficiencies, (2) geographic distribution of households, (3) appliance efficiency, (4) size of dwelling units, (5) fuel switching, and (6) consumer attitudes.

The most important factor identified was improved building shell efficiency, although the impact of appliance efficiency is growing rapidly. Due to data 1 imitations, PNL was not able to quantify the effects of two factors (size of dwelling units and fuel switching) within the framework of this study. The total amount of the energy reduction explained ranged from 18 to 46 percent over the years 1974 to 1980. 


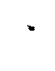

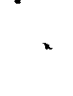




\section{CONTENTS}

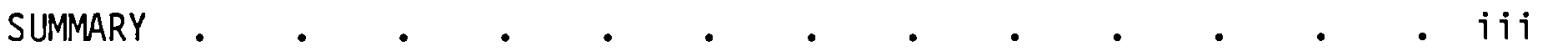

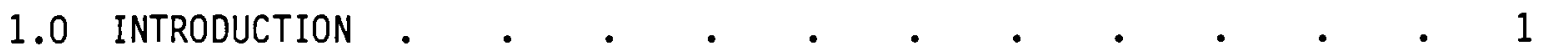

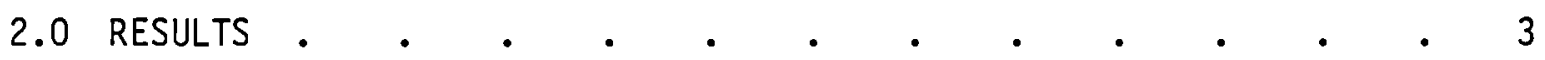

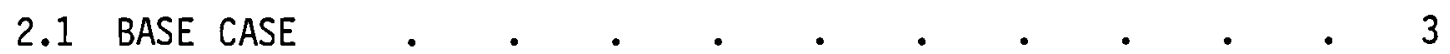

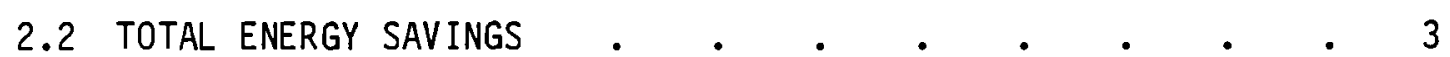

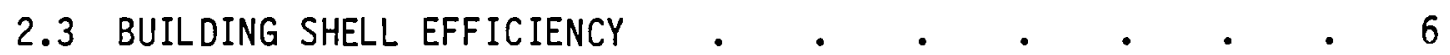

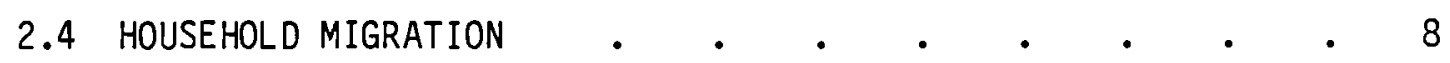

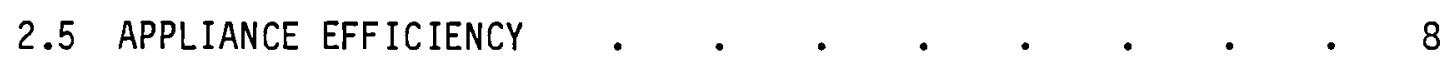

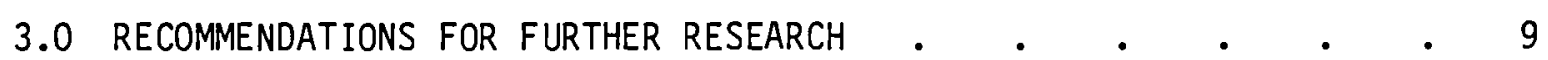

3.1 ANALYSIS OF RECS DATA $\quad$ •

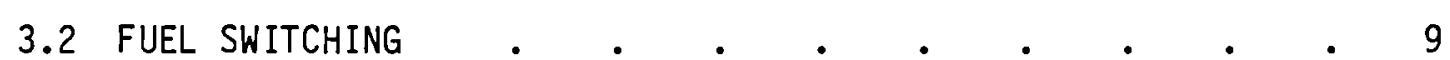

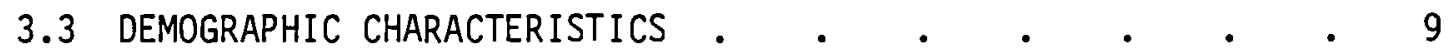

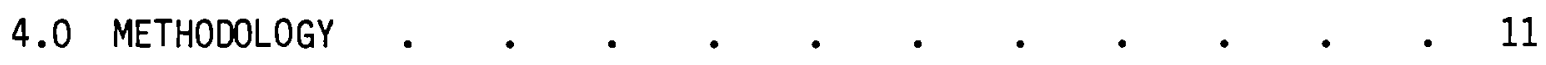

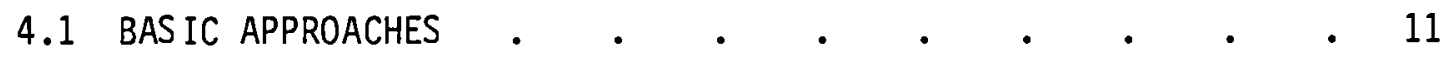

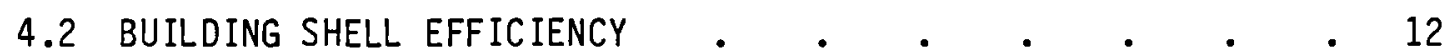

4.3 GEOGRAPHIC DISTRIBUTION OF HOUSEHOLOS • • • • • • • 18

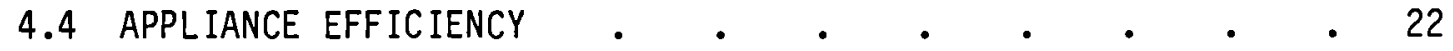

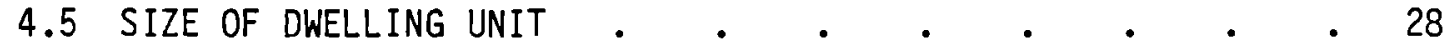

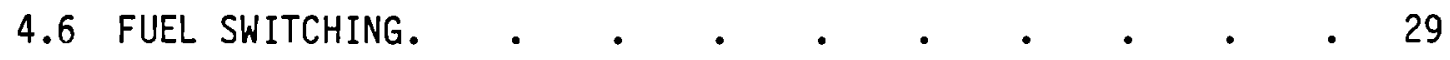

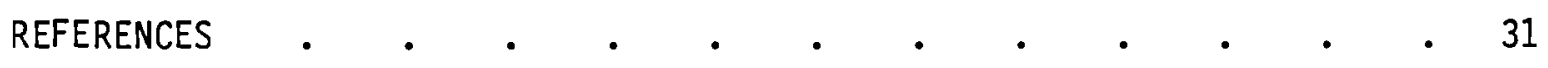


$\checkmark$

, 


\subsection{INTRODUCTION}

Energy used by households in 1980 was a little over 15 Quads ( 1 Quad = 1 quadrillion Btu), roughly equal to 20 percent of all energy consumption in the U.S. As in other sectors in the economy, the trend of residential energy use changed abruptly after 1973. On a per-household basis, residential energy use grew at an annual rate of some 2.2 percent per year between 1960 and 1973. Between 1973 and 1980, energy use per household fell approximately 1.7 percent annually.

The objective of this report is to examine the key factors that have contributed to the decline in residential energy use from 1973 to 1980 . This analysis is part of a broader effort on the part of the Department of Energy's Office of Policy, Planning, and Analysis (PPA) to assess the post-embargo record of energy conservation in a number of key sectors of the economy. This overall assessment is intended to provide insights as to areas in which both market forces and governmental actions have contributed to the decline in energy use.

The remainder of this report is divided into three sections. Section 2 summarizes the results of the research that has been performed by the Pacific Northwest Laboratory (PNL). Preliminary estimates of the average energy savings per household have been decomposed into six categories. These include energy savings due to:

- increases in building shell efficiencies

- changes in the geographic distribution of households

- increases in appliance efficiency

- changes in floor space

- changes in fuel source

- changes in attitudes (a residual category).

Section 3 presents the recomendations for further research, while Section 4 describes the methodology employed by PNL. 


\subsection{RESULTS}

\subsection{BASE CASE}

The factors leading to reduced residential energy demand are analyzed by comparing actual demand to a "base case" demand. The "base case" demand in this analysis is computed by holding the energy consumption per household fixed at its 1973 level. Thus, the growth in total energy consumption in the base case parallels the growth in the number of households.

The top edge of the graph in Figure 2.1 illustrates the "base case" demand. Using the 1973 figure of $220.1 \mathrm{MMBtu} /$ household, total energy use would have grown from 15.1 Quads in 1973 to 17.69 Quads in 1980. Thus, even excluding the pre-embargo trends of increased energy use per household, energy use still would have grown by 17 percent on the basis of household formation growth alone.

The bottom line of the graph shows actual energy consumption in the residential sector. Data for 1973 through 1979 were taken from the 1980 State Energy Data System (SEDS) annual report, while 1980 data were estimated by PNL as part of its Energy Conservation Indicators project for DOE.

\subsection{TOTAL ENERGY SAVINGS}

The area between the two curves represents the energy savings in the residential sector over the study period. This area, the annual residential energy savings, is allocated among six separate components:

- building shell efficiency

- household migration

- appliance efficiency

- dwelling unit size

- fuel substitution

- attitudes towards conservation.

PNL has been successful in identifying four of these changes: the impacts of building shell efficiency, household migration, appliance efficiency, and dwelling unit size. On the basis of data from the National Interim Energy Consumption Survey, there was no significant change in the average size of dwelling units over the period, so this impact has been excluded from further research. The available data on the use of fuels did not allow the estimation 


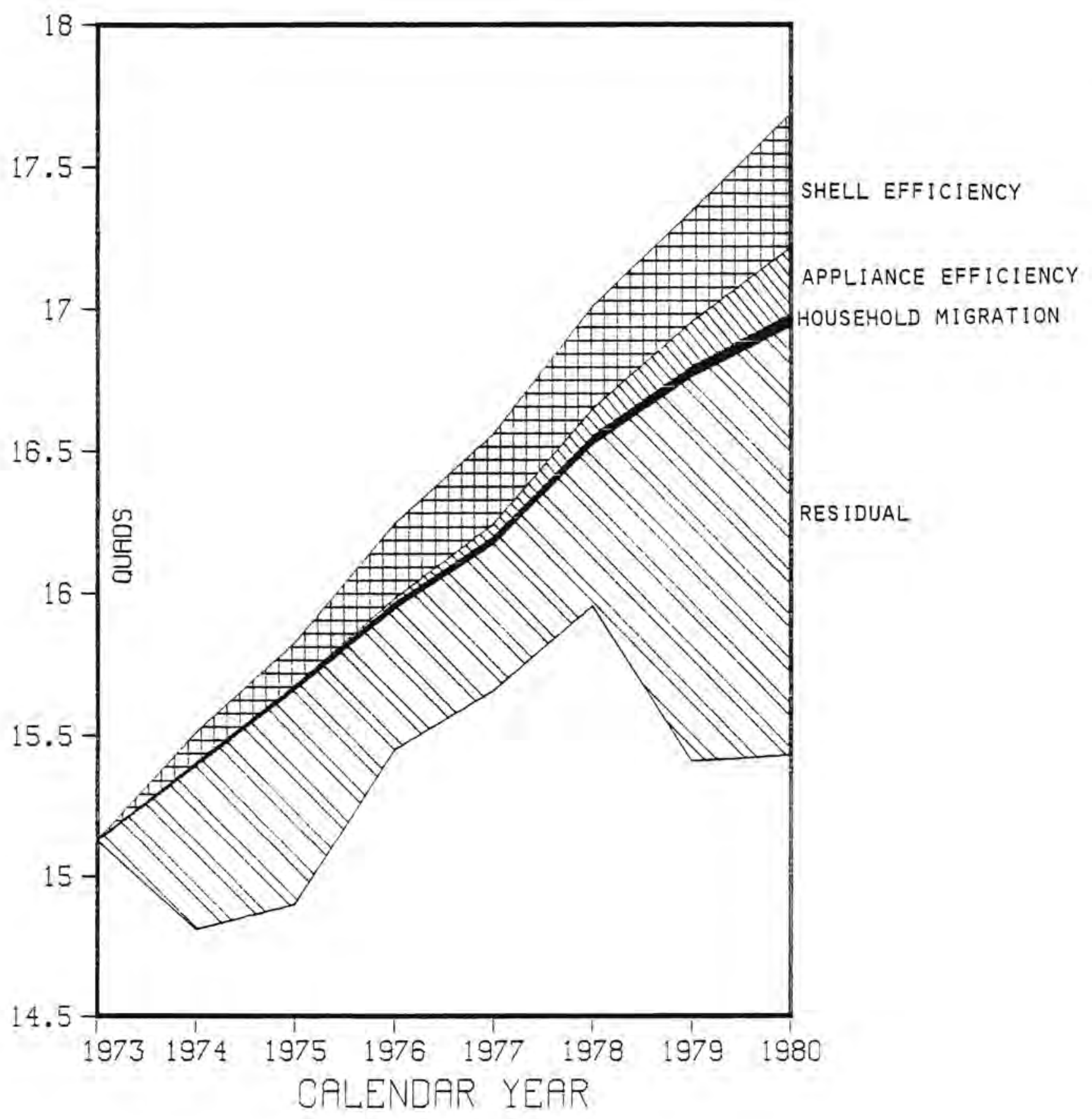

FIGURE 2.1 Components of Residential Energy Savings 
of the impact of fuel switching. The residual category of Figure 2.1, therefore, contains both the impacts of fuel switching and of consumer attitudes towards conservation.

Table 2.1 presents this information in tabular format. Column 1 shows the total energy savings, measured in terms of quadrillion Btu. Columns 2-4 show the savings estimates attributable to each of the factors explicitly considered thus far. The last column shows the residual category.

If we look first at 1980, the largest contribution (approximately 23 percent) to the reduction in total energy use is attributed to changes in the efficiency of the building envelope. Appliance efficiency changes account for 10 percent of the total change in 1980; the impact from this factor is growing rapidly. Population migration from the Snow Belt to the West and South is the smallest effect isolated, accounting for approximately 2 percent of the total change (aga in, in 1980).

TABLE 2.1. Components of Energy Savings, 1974-1980

\begin{tabular}{|c|c|c|c|c|c|}
\hline Year & $\begin{array}{c}\text { Energy Savings } \\
\text { Tota1 Change } \\
\text { (Quads) } \\
\end{array}$ & $\begin{array}{c}\text { Shell } \\
\text { Efficiency } \\
\text { (Quads) }\end{array}$ & $\begin{array}{l}\text { Household } \\
\text { Migrat ion } \\
\text { (Quads) } \\
\end{array}$ & $\begin{array}{l}\text { Appliance } \\
\text { Efficiency } \\
\text { (Quads) } \\
\end{array}$ & $\begin{array}{l}\text { Residual } \\
\text { (Quads) }\end{array}$ \\
\hline $\begin{array}{l}1974 \\
1975 \\
1976 \\
1977 \\
1978 \\
1979 \\
1980\end{array}$ & $\begin{array}{r}.70 \\
.93 \\
.79 \\
.90 \\
1.05 \\
1.93 \\
2.25\end{array}$ & $\begin{array}{l}.12 \\
.17 \\
.29 \\
.35 \\
.39 \\
.42 \\
.51\end{array}$ & $\begin{array}{l}.01 \\
.01 \\
.02 \\
.03 \\
.03 \\
.04 \\
.04\end{array}$ & $\begin{array}{l}0 \\
0 \\
.02 \\
.05 \\
.010 \\
.16 \\
.23\end{array}$ & $\begin{array}{r}.57 \\
.75 \\
.47 \\
.49 \\
.53 \\
1.31 \\
1.46\end{array}$ \\
\hline
\end{tabular}

Overa 11, the percentage of the change in energy consumption explained by these three components ranges from 18 percent in 1974 to 46 percent in 1977 . The three components, however, are mainly longer term adjustments to changes in energy prices, income, etc. It is interesting to note, therefore, that the years in which the residual component grows relative to these three parts are the years in which there were large energy price increases: 1974, 1979, and 1980. As previously stated, a major component of this residual term is consumers' attitudes towards conservation, which include the impacts of reducing hot water use, setting back thermostats, employing shower restricters, and other short-term, relatively simple adjustments. 
The remainder of this section will discuss each of the effects in more detail.

\subsection{BUILDING SHELL EFFICIENCY}

The impact of building shell efficiency changes is based on work done by Adams and Rockwood (1981). Between 1973 and 1980, the average year-to-year change in energy savings per household was .838 million Btu. Higher-thanaverage increases occurred during the periods 1973-1974 (1.520 MMBtu), 19751976 (1.481 MMBtu) and 1979-1980 (.942 MMBtu). This general pattern was common to a 11 three end uses (gas heating, electric heating, and electric air conditioning). Table 2.2 displays some elements in the pattern. The 1973-1974 rise in energy savings appears to have been due primarily to increases in shell efficiency caused by increases in the prices of natural gas and electricity. Above-average savings during the period 1975-1976 appear to have been due to the combined effects of the post-recession surge in household income and rising natural gas prices on housing shell efficiencies. The final surge in energy savings during 1979-1980 was due almost entirely, it seems, to the effect of energy price increases on shell efficiencies.

TABLE 2.2. Components of Energy Savings per Household, 1974-1980

\begin{tabular}{|c|c|c|c|c|c|}
\hline Year & $\begin{array}{l}\text { Base-Actua } 1 \\
\text { (MMBTU/HH) }\end{array}$ & $\begin{array}{l}\text { Shell } \\
\text { Efficiency } \\
\text { (MMBTU/HH) }\end{array}$ & $\begin{array}{l}\text { Household } \\
\text { Migration } \\
\text { (MMBTU/HH) }\end{array}$ & $\begin{array}{l}\text { Appliance } \\
\text { Efficiency } \\
\text { (MMBTU/HH) }\end{array}$ & $\begin{array}{c}\text { Residual } \\
\text { (MMBTU/HH) }\end{array}$ \\
\hline $\begin{array}{l}1974 \\
1975 \\
1976 \\
1977 \\
1978 \\
1979 \\
1980\end{array}$ & $\begin{array}{r}9.96 \\
12.90 \\
10.75 \\
12.00 \\
13.59 \\
24.51 \\
28.04\end{array}$ & $\begin{array}{l}1.70 \\
2.29 \\
3.90 \\
4.62 \\
5.09 \\
5.37 \\
6.40\end{array}$ & $\begin{array}{l}.14 \\
.19 \\
.28 \\
.33 \\
.38 \\
.47 \\
.55\end{array}$ & $\begin{array}{l}0 \\
0 \\
.20 \\
.60 \\
1.21 \\
1.98 \\
2.86\end{array}$ & $\begin{array}{r}8.12 \\
10.42 \\
6.37 \\
6.45 \\
6.91 \\
16.69 \\
18.23\end{array}$ \\
\hline
\end{tabular}

Table 2.3 decomposes the cumulative energy savings per household due to changes in shell efficiency into two distinct elements. The cumulative savings shown in column 1 represent the energy savings that would have occurred if households had not adjusted their behavior in response to the "comfort effect" (as the level of shell efficiency increases, the cost of comfort decreases) 
created by space conditioning. As such, these energy savings are due purely to the fact that additional comfort can be provided to the household using less energy than before. The cumulative savings in column 2, on the other hand, represent the decreased savings that occur when households actually do adjust their thermostats in response to the comfort effect. Note that the two effects move in opposite directions. Their combined totals, shown in column 3, represent the cumulative net energy savings due to changes in housing shell efficiency -- the same savings shown in column 2 of Table 2.2.

TABLE 2.3. Components of Energy Savings Per Household due to Changes in Shell Efficiency (MMBtu/HH)

\begin{tabular}{|c|c|c|c|}
\hline Year & $\begin{array}{c}\text { Efficiency } \\
\text { Effect } \\
\end{array}$ & $\begin{array}{l}\text { Comfort } \\
\text { Effect }\end{array}$ & $\begin{array}{c}\text { Net } \\
\text { Savings }\end{array}$ \\
\hline 1974 & 4.85 & -3.15 & 1.70 \\
\hline 1975 & 6.37 & -4.08 & 2.29 \\
\hline 1976 & 10.65 & -6.75 & 3.90 \\
\hline 1977 & 12.47 & -7.85 & 4.62 \\
\hline 1978 & 13.67 & -8.58 & 5.09 \\
\hline 1979 & 14.35 & -8.98 & 5.37 \\
\hline 1980 & 17.00 & -10.60 & 6.40 \\
\hline
\end{tabular}

One weakness inherent in these numbers comes from the computation of the shell efficiencies. The National Interim Energy Consumption Survey (NIECS), which was used to estimate the efficiencies, did not measure the consumption of fuel 0 il. Therefore, the results of this analysis are based on the assumption that households that use fuel oil responded in the same manner as households using natural gas or electricity. This assumption, unfortunately, is rather untenable, and the energy savings due to building shell efficiency changes are understated (since fuel oil prices increased much more rapidly than electricity or natural gas prices), especially in the periods of rapid fuel oil price increases (1974, 1979, and 1980). 


\subsection{HOUSEHOLD MIGRATION}

Column 3 in Table 2.2 presents the per-household energy savings due to the migration of households from the northern states to warmer climates. The total energy saved due to population movements is small, but total residential energy savings due to population shifts has been growing steadily over the study period. In general, migration occurs rather gradually over long periods of time, thus accounting for the magnitude of this effect.

\subsection{APPLIANCE EFFICIENCY}

Column 4 of Table 2.2 presents our estimates of energy savings that can be attributed to a more efficient stock of appliances used by households. This effect is growing rapidly as new, more efficient, units are incorporated into the existing stock. Manufacturers in the late 1970's began marketing more efficient models, in response to higher energy prices as well as the imposition (realized and potential) of energy standards by the federal and state governments.

The term "appliance" is a broad one here in that it includes central heating and air conditioning equipment. Direct survey data on the efficiency of appliances sold is available only for 1972 and 1978. As the discussion in Section 4.4 indicates, a number of assumptions were required in order to derive quantitative estimates of the impact of this component over each of the years between 1973 and 1980. Accordingly, no estimate of the standard error associated with these values can be given; however our judgment is that the estimates are reasonable as compared to the other components shown in Table 2.2. 


\subsection{RECOMMENDATIONS FOR FURTHER RESEARCH}

There are basically three areas in which further research can improve the results of this study: analysis of the Residential Energy Conservation Survey (RECS), additional research on fuel switching, and further development of demographic impacts.

\subsection{ANALYSIS OF RECS DATA}

When the RECS data is available, it will provide:

- better information on fuel oil consumption

- more detailed information on the thermal characteristics of dwellings

- a time series of observations combined with NIECS

- data on use of wood for space heating.

The RECS data could be used to re-estimate the Adams and Rockwood model (from the 1981 PNL study described in Section 4.0) in a time-series framework, with fuel oil included as a space heating fuel. This would strengthen and yield a dynamic interpretation to the results. The RECS data could also be used to verify the results related to the size of of the dwelling unit and could provide information on fuel switching.

\subsection{FUEL SWITCHING}

As stated in Section 2, this is one of the most important components of residential energy savings, as wood is not included in the SEDS data. A number of data sources (including the 1980 Census, RECS, and a nationwide survey by the Forest Service) will become available in the near future. Over time these data may allow the identification of this effect. Unfortunately, current data sources do not allow such disaggregation.

\subsection{DEMOGRAPHIC CHARACTERISTICS}

The results of the research documented here do not allow for changes in the demographic composition of households (such as number of members and the age distribution). Additional research will be required to ascertain the impacts of other demographic characteristics. 


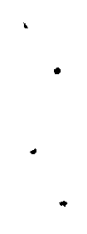




\subsection{METHODOLOGY}

\subsection{BASIC APPROACHES}

There are essentially two different ways of decomposing changes in household energy use. The first approach focuses on the determinants of residential energy demand, as derived from the theory of consumer behavior. From this perspective, variations over time in the amount of energy consumed can be traced to changes in the following variables:

- the price of energy relative to the prices of other goods and services available in the marketplace

- the amount of income which the household has to spend on the goods and services which it consumes

- weather

- the size of the household and the age distribution of its membership.

A change in any of these causal variables (with the possible exception of the last one) will cause household members to alter their behavior in some fashion that will ultimately change in the amount of energy consumed.

A second method of decomposing changes in household energy use involves isolating the effect of different types of household behavior on residential energy demand, irrespective of the source of these behavioral changes. As such, this method involves determining what the household does in response to changes in the causal variables described above. Usirig this type of approach, changes in residential energy use would be decomposed into changes in the following effect variables:

- changes in building shell efficiencies

- changes in the geographic distribution of households

- changes in appliance efficiency

- changes in the size of dwelling units

- fuel switching

- changes in attitudes towards conservation. 
The second method is the approach employed in this study. The change in residential energy use per household between 1973 and 1980 is allocated to each of the first five effects identified above. However, since all of the effects are not independent (i.e., changes in shell efficiency probably vary by climate zone), the change in energy consumption due to attitude shifts towards conservation cannot be uniquely defined.

In this study, therefore, only the direct impacts of the above effect variables will be considered. The remainder of this section describes the methodology employed in isolating each of the effect variables.

\subsection{BUILDING SHELL EFFICIENCY}

In the Adams and Rockwood study, 1981, relevant characteristics of residential structures as reported in the National Interim Energy Consumption Survey (NIECS) were used in conjunction with the DOE-2 Building Thermal Analysis Program to construct an index of shell thermal efficiency for each structure in the sample data as regression analysis was then performed to explain the cross-sectional variation in housing shell efficiency in terms of the variation in a set of explanatory variables. The form of the regression equation used in this analysis can be expressed generally as:

$$
\theta=f(P e, P g, H D D, Y, A G E, F g, S F)
$$

where

$$
\begin{aligned}
\theta & =\text { thermal efficiency index } \\
P_{e} & =\text { price of electricity } \\
P_{g} & =\text { price of natural gas } \\
H D D & =\text { heating degree days } \\
Y & =\text { household income } \\
A G E & =\text { age of structure } \\
F_{g} & =\text { a dummy variable equal to } 1 \text { if the primary heating fuel was } \\
& \text { natural gas, } 0 \text { otherwise; }
\end{aligned}
$$


The empirical results from this equation are presented in Table 4.1. The adjusted $R^{2}$ is 0.559 , indicating that over half of the variance in the level of thermal efficiency $(\theta)$ is explained via the explanatory variables in the equation. The fuel price elasticities for thermal efficiency are positive, as expected, with the electricity price elasticity (.281) being slightly higher than the natural gas price elasticity (.204). These fuel price elasticities imply that a 1 percent increase in the price of natural gas would result in a .2 percent increase in thermal efficiency. For those heating with electricity, a 1 percent increase in the price of electricity would result in a .28 percent increase in thermal efficiency.

TABLE 4.1. Empirical Results of the Thermal Efficiency Equation

\begin{tabular}{lcc} 
Variable & Coefficient & Standard Error \\
\cline { 2 - 3 } Intercept & 0.542 & 0.336 \\
In $P_{e}$ & $0.281^{(a)}$ & 0.078 \\
In $P_{g}$ & $0.204^{(a)}$ & 0.061 \\
In HDD & $0.194^{(a)}$ & 0.031 \\
In $Y$ & 0.031 & 0.021 \\
AGE & $0.004^{(a)}$ & 0.001 \\
$F$ g & $-0.403^{(b)}$ & 0.209 \\
SF & $-1.784^{(a)}$ & 0.046 \\
$R^{2}=0.559$ & & \\
Observations $=1,458$ &
\end{tabular}

(a) Significant at the $1 \%$ level.

(b) Significant at the $10 \%$ level.

In this study, Equation (1) was used to predict average shell efficiency index numbers for three end uses -- gas heating, electric heating and electric air conditioning -- for the period 1973 for 1980. This effort involved the construction of a consistent set of explanatory variables for the non-sampled years, 1973-1977 and 1979-1980. 
The first step in this procedure was to divide the households in the NIECS data into six separate climate zones. With in each climate zone, households were further broken down by primary heating fuel (gas or electricity) and by type of housing unit (single or multi-family). This breakdown by climate zone, heating fuel, and dwelling type resulted in 24 subsets of the NIECS data base. Next, the average values for the explanatory variables shown in Equation (1), not including the dummy variables, were calculated for each of these 24 groups of households for 1978 . Estimates of the values of these variables during the remaining years (1973-1977 and 19791980) were constructed using national data and the 1978 regional-to-national ratio for each variable.

In the strictest sense, the data series produced by this method can be used only in conjunction with Equation (1) to predict disaggregated values of shell efficiency index for gas and electric space heating. To construct a disaggregated shell efficiency index for electric air conditioning would have required splitting each of the 24 groups in the NIECS data base into two additional groups based on the presence or absence of an electric air conditioning unit. This approach was rejected because (a) the standard errors of the disaggregated 1978 values for $P_{e}, P_{g}$, HDD and AGE using this classification scheme were in many cases more than three times greater than the corresponding standard errors of these variables for the existing breakdown; and (b) the re-estimation of Equation (1) by adding an electric air conditioning dummy variable did not significantly improve its explanatory power. Therefore, the shell efficiency of a housing unit with electric air conditioning was assumed to be the same as the shell efficiency of a housing unit that was identical to it in all other respects, except for the presence of that end-use technology.

Having constructed the necessary input values for Equation (1), the next step of the analysis consisted of estimating the 24 sets of shell efficiency indexes using these explanatory variables. These computed shell efficiency indexes were then transformed into six regional climate zone averages for gas heating, electric heating and electric air conditioning by the following method. Let $\theta_{i j}^{r}$ represent the disaggregated shell efficiency estimate in region $r$ for primary heating fue $1 i$, for housing type $j$, and let $a_{i j}^{r}$ represent the percentage of total housing units in region $r$, also stratified as heating fue 1 and housing type in region $r$. Then the average shell efficiency index for heating fuel $i$ in region $r$ is: 


$$
\theta_{i}^{r}=\sum_{j=1}^{2} a_{i j}^{r} \theta_{i j}^{r}
$$

For electric air conditioning, the average efficiency must be aggregated from both gas and electric space heating end uses, as electric air conditioning may be present in a house with either gas or electric space heating. If $p_{i j}^{r}$ represents the percentage of housing units with electric air conditioning in region $r$, of housing type $j$, using heating fue $1, i$, then the average she 11 efficiency index for air conditioning in region $r$ is:

$$
\theta_{A C}^{r}=\sum_{i=1}^{2} \sum_{j=1}^{2} p_{i j}^{r} \theta_{i j}^{r}
$$

The next step of the analysis consisted of calculating the rates of change over time, between 1973 and 1980, for $r_{i}$ and $\underset{A C}{r}$. In the case of electric space heating, $\underset{i}{ }$ was first averaged for the nation as a whole according to:

$$
\theta_{E}=\sum_{r=1}^{6} e^{r} \theta_{E}^{r}
$$

where $e^{r}$ represents the percentage of households in region $r$ using electricity as their primary heating fuel. The rates of change for $E$ were then calculated simply as:

$$
\dot{\Delta}_{E t}=\frac{\theta_{E t+1}-\theta_{E t}}{\theta_{E t}}
$$

The regional rates of change for $\theta_{i}^{r}$ and $\theta_{A C}^{r}$, or $\dot{\Delta}_{G t}$ and $\dot{\Delta}_{A C t}$, were calculated according to the same method.

In the study cited above (Adams and Rockwood 1981), PNL utilized the NIECS data base to derive a set of shell efficiency elasticities of energy demand for electric space heating, gas space heating and electric air conditioning. The elasticity estimate for electric space heating was developed for the nation as 
a whole (hence the need to aggregate $\theta_{E}^{r}$ to $\theta_{E}$ ), while the elasticities for the two remaining end uses were estimated at the regional level. Conceptually, each of these elasticities represents the percentage change in energy consumption by a specific end use due to a one percent change in the associated shell efficiency index. Therefore, the annual rates of change in energy consumption due to changes in shell efficiency can be calculated by multiplying the rate of change of the average shell efficiency index for a given end use by its corresponding elasticity estimate.

For electric heating, this procedure yields a time series of national estimates for the percentage changes in energy consumption during the period 1973-1980. For the remaining two end uses, national estimates of these percentages in energy consumption must be calculated as a weighted average of the regional estimates using the same general weighting procedure shown in Equation (4).

Calculating the actual year-to-year changes in energy consumption for each of the end uses defined above requires seperate base period estimates of the average amount of energy consumed for each of these end uses. A number of such estimates are available from secondary sources. However, the year in which separate estimates have been made for each end use are not consistent and estimates of energy consumption for individual end uses vary by as much as 30 percent. Therefore, composite values for average energy use for each of the three end uses were constructed from estimates provided in Hartman and Werth (1979), and these composite values were arbitrarily based in the year 1973 . These estimates are shown in Table 4.2.

TABLE 4.2. Average Energy Use by End Use

\begin{tabular}{lc}
\multicolumn{1}{c}{ Appliance } & $\begin{array}{c}\text { Energy Use } \\
\text { (MMBtu/yr/unit) }\end{array}$ \\
Electric Space Heat & 121.62 \\
Central Air & 36.42 \\
Room Air & 15.92 \\
Gas Space Heat & 95.10
\end{tabular}

Source: Hartman and Werth 1979. 
Estimates of annual energy savings per household due to changes in shell efficiency for each of the three end uses were then calculated as:

$$
\Delta E_{i t}=b_{i t} E_{i t}
$$

where the subscript $i$ now denotes the three end uses, $E_{i t}$ is the change in per-household energy consumption associated with end use $i$, and $b_{i t}$ is the annual rate of change of energy consumption for end use $i$. and $E_{i t}$ is the corresponding value of energy consumption for end use $i$ in period $t$. Since $E_{i 0}$ is defined for each end use, $E_{i t+1}$ can be calculated from Equation (6) on an iterative basis as:

$$
E_{i t+1}=\left(b_{i t}+1\right) E_{i t}
$$

Aggregate estimates for the average change in energy consumption per household by all end uses can then be calculated as a household-weighted average of the individual $E_{i t}$. Thus, if $p_{i t}$ represents the proportion of households in the nation in which end use $i$ is present, the average change in energy consumption per household due to increases in shell efficiency in each year is simply:

$$
E_{t}=\sum_{i} p_{i t} E_{i t}
$$

Implicit in the preceding analysis is that increases in thermal efficiency have two distinct--and opposing--effects on space conditioning energy usage. First of all, when a residential unit is made thermally more efficient, the marginal cost of providing the comfort associated with space conditioning is reduced. Households will respond to this price decrease by consuming more of the comfort that is "produced" by space conditioning. From a behavioral standpoint, this effect is translated into higher thermostat settings in winter and lower thermostat settings in summer (if space cooling is used in the home). However, increasing the thermal efficiency of a residential unit has the effect of reducing the amount of energy required to provide each additional unit of comfort. Ceteris paribus, energy consumption will be reduced. This impact is the "comfort effect" described in Section 2.3. 
Note that the comfort effect and the efficiency effect work in opposite directions. The comfort effect tends to increase energy use through increased comfort levels, while the efficiency effect reduces the amount of energy required to produce either a net increase or decrease in the amount of energy consumed by space conditioning, depending on the relative magnitude of the two effects. However, the shell efficiency elasticities of energy demand estimated by PNL, for all three space conditioning end uses, are negative. Therefore, increases in building shell efficiencies should produce net energy savings in the three space conditioning end-use categories identified.

Nonetheless, it should be observed that, for any individual end use, those energy savings which do occur will be directly proportional to the increase in thermal efficiency only if the price effect is zero. This will be true only if the demand for the comfort provided by that end use is perfectly price inelastic--in other words, when households do not vary thermostat settings in response to changes in the implicit price of the comfort goal.

Therefore, it is of some interest to determine how much energy would have been saved if households had not adjusted thermostat settings in response to changes in housing shell efficiencies; i.e., the assumption of a zero comfort effect. In the Adams and Rockwood report, PNL showed that the shell efficiency elasticity of energy demand associated with a specific space conditoning end use is equal to one plus the value of the price elasticity of energy demand for that end use. If the demand for comfort is perfectly price inelastic, then the price elasticity of energy demand for that end use will be zero. Therefore, the change in energy use will be directly proportional to the change in shell efficiency; i.e., the shell efficiency elasticity of energy demand will be equal to one.

To determine the energy savings that would have occurred in the absence of the price effect, therefore, we need only to aggregate the average shell efficiency index for each end use in the same manner as described previously.

\subsection{GEOGRAPHIC DISTR IBUTION OF HOUSEHOLDS}

Population migration from colder states to the Sun Belt over the past decade has contributed to the reduction of residential energy use. In order to measure this impact, a data series was constructed to simulate national energy use per household in the absence of population shifts. By comparing this series with a base period value, a measure of the change in energy consumption due solely to the redistribution of population is derived. 
The national intensity of energy use (per household) can be constructed via a weighted average (where the weights are the proportion of households in the region) of each region's intensity of use:

$$
E_{t}=\sum_{r=1}^{R} P_{r t} E_{r t}
$$

where:

$$
\begin{aligned}
E_{t} & =\text { national energy use per household in time period } t \\
E_{r t} & =\text { energy use per household in state } r \text { at time } t \\
P_{r t} & =\text { proportion of U.S. households residing in state } r \text { at time } t \\
R & =\text { number of regions. }
\end{aligned}
$$

To determine the intensity of household energy use as if the household migration had not occurred, the proportion of households is allowed to vary while holding the regional intensities at their 1973 values $\left(E_{r 73}\right)$ :

$$
E_{t}=\sum_{r=1}^{R} P_{r 73} E_{r t}
$$

where:

$$
\begin{aligned}
E_{t}= & \text { national energy use per household in time period } t \text { if only } \\
& \text { redistribution had occurred. }
\end{aligned}
$$

Finally, the change in energy use per household due to migration is found by subtracting the base year intensity from the constructed series:

where:

$$
\Delta_{t}=\bar{E}_{t}-E_{t}
$$

$$
\Delta_{t}=\begin{gathered}
\text { change in residential energy use due to regional redistribution of } \\
\text { households. }
\end{gathered}
$$


In order to calculate this impact, it was necessary to have information on household energy consumption by region. Using the State Energy Data System (SEDS) total residential energy consumption series and a constructed state level household series, a time series of regional energy use intensities was constructed.

State estimates of the number of households were obtained from Statistical Abstract of the U.S. for 1973-1978 and from the Census for 1980. Unfortunately, the Statistical Abstract series (which is based on the 1970 Census and subsequent Current Population Report surveys) was not consistent with the 1980 Census figures, so it was impossible to interpolate values for 1979. Accordingly, a correction procedure was applied, as described below.

First, trend lines were developed for each state and used to predict the number of households in 1979 and 1980. Next, the percentage error in 1980 was calculated with the 1980 Census numbers. Finally, the Statistical Abstract series (including the 1979 predicted values) were corrected by linearly allocating the percentage error to the 1974-1979 years:

$$
\hat{H H}_{r t}=\frac{t}{7} \times P E_{r}+H H_{r t}
$$

where:

$$
\begin{aligned}
\hat{H H} H_{r t} & =\text { adjusted household series } \\
t & =\text { index for year }(0=1973, \ldots, 7=1980) \\
P E_{r} & =\text { percentage error in } 1980 \\
H H_{r t} & =\text { Statistical Abstract household series. }
\end{aligned}
$$

These adjusted series were used to construct both the national and regional use per household series, and are shown in Table 4.3. 
TABLE 4.3. Adjusted Household Series, 1973-1980 (Thousands)

\begin{tabular}{|c|c|c|c|c|c|c|c|c|}
\hline $\begin{array}{l}\text { STATE } \\
* * * * *\end{array}$ & $\begin{array}{c}1973 \\
* * * * * * *\end{array}$ & $\begin{array}{c}1974 \\
* * * * *\end{array}$ & $\begin{array}{c}1975 \\
* * * * * *\end{array}$ & $\begin{array}{c}1976 \\
* * * * * *\end{array}$ & $\begin{array}{c}1977 \\
* * * * * *\end{array}$ & $\begin{array}{c}1978 \\
* * * * * *\end{array}$ & $\begin{array}{c}1979 \\
* * * * * * *\end{array}$ & $\begin{array}{r}1980 \\
* * * * * *\end{array}$ \\
\hline $\mathrm{AK}$ & 90 & 92 & 102 & 114 & 114 & 115 & 125 & 131 \\
\hline$A L$ & 1117 & 1148 & 1182 & 1216 & 1244 & 1283 & 1313 & 1341 \\
\hline $\mathrm{AR}$ & 680 & 701 & 724 & 739 & 755 & 781 & 798 & 815 \\
\hline A Z & 663 & 721 & 758 & 797 & 833 & 884 & 924 & 956 \\
\hline $\mathrm{CA}$ & 7191 & 7392 & 7515 & 7752 & 7960 & 8247 & 8399 & 8620 \\
\hline $\mathrm{CO}$ & 810 & 851 & 883 & 919 & 952 & 998 & 1030 & 1050 \\
\hline $\mathrm{CT}$ & 995 & 1004 & 1020 & 1037 & 1048 & 1061 & 1076 & 1093 \\
\hline DC & 272 & 271 & 263 & 260 & 257 & 256 & 252 & 252 \\
\hline DE & 180 & 183 & 188 & 192 & 195 & 199 & 203 & 207 \\
\hline FL & 2741 & 2968 & 3100 & 3223 & 3328 & 3484 & 3633 & 3741 \\
\hline GA & 1504 & 1565 & 1617 & 1671 & 1723 & 1777 & 1831 & 1872 \\
\hline $\mathrm{HI}$ & 234 & 240 & 253 & 262 & 269 & 275 & 286 & 294 \\
\hline IA & 956 & 957 & 978 & 998 & 1007 & 1026 & 1038 & 1052 \\
\hline ID & 248 & 261 & 269 & 281 & 293 & 304 & 315 & 324 \\
\hline IL & 3674 & 3710 & 3760 & 3823 & 3879 & 3944 & 3990 & 4042 \\
\hline IN & 1713 & 1757 & 1774 & 1807 & 1833 & 1880 & 1901 & 1926 \\
\hline $\mathrm{KS}$ & 771 & 782 & 795 & 812 & 825 & 845 & 856 & 872 \\
\hline KY & 1062 & 1091 & 1121 & 1157 & 1177 & 1210 & 1239 & 1263 \\
\hline LA & 1141 & 1177 & 1213 & 1263 & 1298 & 1341 & 1379 & 1411 \\
\hline MA & 1879 & 1895 & 1920 & 1942 & 1956 & 1986 & 2005 & 2032 \\
\hline$M D$ & 1282 & 1305 & 1332 & 1359 & 1380 & 1409 & 1433 & 1460 \\
\hline$M E$ & 332 & 339 & 350 & 360 & 369 & 377 & 387 & 395 \\
\hline$M I$ & 2845 & 2899 & 2936 & 2989 & 3034 & 3108 & 3145 & 3195 \\
\hline MN & 1244 & 1278 & 1296 & 1332 & 1354 & 1394 & 1417 & 1445 \\
\hline MO & 1617 & 1640 & 1654 & 1689 & 1707 & 1752 & 1768 & 1793 \\
\hline$M S$ & 697 & 715 & 734 & 756 & 775 & 792 & 812 & 827 \\
\hline $\mathrm{MT}$ & 241 & 245 & 251 & 258 & 261 & 273 & 276 & 283 \\
\hline 110 & 1659 & 1718 & 1785 & 1832 & 1880 & 1939 & 1995 & 2040 \\
\hline IID & 197 & 201 & 204 & 211 & 215 & 217 & 223 & 227 \\
\hline $\mathrm{NE}$ & 512 & 523 & 527 & 539 & 545 & 554 & 562 & 571 \\
\hline $\mathrm{NH}$ & 254 & 263 & 271 & 281 & 293 & 306 & 314 & 323 \\
\hline if J & 2365 & 2381 & 2404 & 2441 & 2460 & 2494 & 2517 & 254 \\
\hline IIM & 333 & 350 & 364 & 380 & 395 & 412 & 427 & 440 \\
\hline IV & 188 & 209 & 221 & 238 & 255 & 276 & 292 & 304 \\
\hline NY & 6182 & 6176 & 6180 & 6249 & 6240 & 6261 & 6288 & 6339 \\
\hline $\mathrm{OH}$ & 3473 & 3529 & 3571 & 3622 & 3658 & 3752 & 3787 & 38 \\
\hline$O K$ & 926 & 959 & 972 & 1008 & 1031 & 1073 & 1093 & 1118 \\
\hline$O R$ & 773 & 812 & 829 & 864 & 395 & 941 & 964 & 991 \\
\hline PA & 3908 & 3943 & 3996 & 4046 & 4078 & 4133 & 4175 & 4220 \\
\hline RI & 312 & 309 & 315 & 323 & 326 & 332 & 335 & 338 \\
\hline $\mathrm{SC}$ & 816 & 853 & 885 & 914 & 938 & 973 & 1003 & 102 \\
\hline SD & 216 & 220 & 223 & 228 & 231 & 235 & 238 & $24 i$ \\
\hline TH & 1327 & 1368 & 1404 & 1455 & 1496 & 1542 & 1583 & 1618 \\
\hline TX & 3793 & 3971 & 4102 & 4312 & 4457 & 4624 & 4792 & 4928 \\
\hline UT & 337 & 355 & 369 & 386 & 401 & 421 & 436 & 44 \\
\hline VA & 1518 & 1562 & 1619 & 1670 & 1721 & 1758 & 1814 & 1862 \\
\hline VT & 146 & 152 & 155 & 160 & 165 & 169 & 174 & 178 \\
\hline WA & 1173 & 1230 & 1280 & 1331 & 1373 & 1453 & 1495 & 1539 \\
\hline$N I$ & 1438 & 1469 & 1492 & 1527 & 1556 & 1594 & 1621 & 1652 \\
\hline WV & 589 & 600 & 612 & 633 & 648 & 658 & 674 & 686 \\
\hline iN $Y$ & 116 & 122 & 129 & 137 & 144 & 153 & 159 & \\
\hline US & 68735 & 70468 & 71894 & 73793 & 75240 & 77270 & 78792 & 8035 \\
\hline
\end{tabular}




\subsection{APPLIANCE EFFICIENCY}

Lawrence Berkeley Laboratory's version of the residential energy use model created by Oak Ridge National Laboratory (ORNL), was used to develop an estimate of the contribution of improved appliance efficiencies to lower household energy consumption. The 0ak Ridge model used in this study includes seven major appliance types as shown below:

- space heating equipment (central and room)

- air conditioners

- water heaters

- refrigerators

- freezers

- ranges and ovens

- dryers

For each appliance type energy consumption is broken out by major fue 1 (electric, gas, and oil) and by type of dwelling unit (single family, multiple family, and mobile home).

Four basic components are needed in order to derive an index (over time) of efficiency for the stock of appliances:

- initial stock of appliances and average energy efficiencies

- penetration rate of new appliances

- usage rates (e.g. hours operated per year)

- efficiency ratings new appliance.

The ORNL model directly provides estimates regarding the first three items above. Information on efficiency ratings for new appliances was gathered through a DOE survey of manufactures (FORM CS-179) in 1979. The CS-179 survey provided data on product efficiency and number of units; an average energy efficiency for each major appliance type was derived from this raw data by using shipments as weights. 
The general approach in using the ORNL model was to calculate the reduction in energy use by allowing only appliance efficiencies to change. In terms of the four factors listed above, both the additions of new appliances and usage rates are not allowed to change in response to greater appliance efficiencies. More specifically, usage rates were held constant and the number of new units installed was calibrated to historical levels.

As a result of deficiencies in the version of the ORNL model employed and with the survey data regarding appliance efficiencies, a number of assumptions were required to derive an annual index of an overall appliance efficiency. The following paragraphs discuss these assumptions in detail.

\section{Efficiency of Existing Stock}

The CS-179 survey asked manufacturers for actual efficiency information on current models (for 1978) and for 1972. With no information to the contrary, Lawrence Berkeley Laboratory (LBL) assumed that the energy efficiencies for appliances sold in 1972 were the most reasonable estimates of the existing stock. Obviously, if the existing stock were less efficient than this value, simple turnover of the stock over the 1972-80 period would, by itself, reduce average energy consumption.

\section{Efficiency of New Appliances}

As mentioned in the previous paragraph, the CS-179 survey applied only years 1972 and 1978. Manufacturers were also asked to provide projections of shipments and efficiency ratings for 1980 appliances. Efficiency improvements for 1978 and 1980, relative to 1972, are shown in Table 4.4. It is assumed that these projections provided a reasonable estimate of realized efficiency for 1980 sales. Efficiency ratings for 1979 were assumed to be the average of the 1978 and 1980 values.

The CS-179 survey did not cover electric space heating units and only conventional electric central air conditioning. Accordingly, electric heat pumps are not included in this study. In the analysis, efficiency of electric central furnaces and room heaters were fixed at their base period of values.

Although the survey showed improvements in appliance efficiencies between 1972 and 1978, there is no available information as to how many of these efficient units were actually in the market place prior to 1978 . Before 1974 there was little incentive to make design improvements to reduce energy consumption. Given the lead time required to get new designs into production, 
TABLE 4.4. Efficiency Improvements for New Adoliances

\begin{tabular}{c}
$\begin{array}{c}\text { Estimated } 1977 \\
\text { Energy IJse, } \\
\text { Ouads }\end{array}$ \\
\hline
\end{tabular}

Central Space Heating*
Gas
$0 \nmid 1$
2.65
1.92
1.4
2.1
5.1
3.2

Air Conditioning

Central 1.25

Room

.41 .

5.0

11. 3

8.4

12.0

Water Heaters

Electric

Gas

1.17

1.1

1.7

1.9

.85

8.0

Refrigerators

1.21

20.5

34.3

Freezers

.45

24.7

32.8

Ranges and Ovens

Electric

Gas

Oryers

Electric

Gas
.41

.07
15.7

27.8

20.1

.31

0.0

13.3
4.2

14.7

₹ Efficiency data for central and room electric heating was not oart of the CS-179 survey. 
it is unlikely that any significant improvements in efficiencies were incorporated in new models before late 1975. Accordingly, in the absence of survey-based information, it was assumed that the change in average efficiency for appliances introduced prior to 1978 followed the schedule below:
1974
1975
no change from 1972
197633 percent of the 1972-1978 CS-179 improvement
197767 percent of the 1972-1978 CS-179 improvement

Adjustment for 1977 Base Year in ORNL Model

The version of the ORNL model used by LBL in this study employs 1977 as a base year. Average energy use per appliance type is estimated for 1977 and on an annual basis for each year up through 1990. From 1977 to 1978 the change in average energy use per appliance (in the stock) is based on the introduction of 1978 efficiency-rated units into an existing stock, whose efficiencies were assumed to be equal to those observed for 1972 .

An estimate, however, is still needed of the changes in average efficiency per unit in the stock prior to 1978. The most desirable means of making this calculation would be to run the ORNL model beginning in 1975, thus adding the more efficient units as outlined in the previous paragraph to the existing stock. However, changing the base year of the ORNL model was not a feasible option within the scope of this study. Accordingly, it was assumed that the rate of stock turnover in 1976 and 1977 was approximately equal to that shown by the ORNL model for 1978. Using this assumption, the change in average efficiency per unit of the stock is then directiy proportional to the efficiency of the new units installed. Thus, the 1975-1976 and 1976-1977 changes are computed to be one-third and two-thirds, respectively, of the change in average unit efficiency shown by the ORNL model for 1977 to 1978 .

To illustrate this procedure, the data for refrigerators can serve as a simple example. The ORNL model showed a per-unit energy consumption by refrigerators at 16.11 MMBtu for 1977 and $15.92 \mathrm{MMBtu}$ for 1978. Using the above procedure, we would fill in energy consumption per unit in prior years as:

$\begin{array}{crcc}1972-1975 & 1976 & 1977 & 1978 \\ 16.30 & 16.24 & 16.11 & 15.92\end{array}$


Referring back to Table 4.4 we note that the CS-179 survey indicates that the average efficiency gain for new refrigerators between 1972 and 1978 was 20.5 percent. On the basis of our assumptions above, in conjunction with the ORNL model results, we conclude that this improvement increased the average efficiency of the stock by a little over two percent (16.30/15.92) between 1972 and 1978.

Use of 1977 Estimated Consumption as Weighting Factors

The previous paragraph described how the energy use per unit of the existing stock (assuming a constant utilization rate) was generated for each individual appliance type. How, then, do we construct an index that represents the average efficiency of the appliance stock as a whole?

To be consistent with the use of 1973 as a base year, it would be desirable to have estimates of energy use for each appliance type in 1973. An aggregate efficiency index would then result from a measure of what the reduction in energy use would have been in order to maintain the same level of energy services yielded by appliances in 1973. The following example should make this procedure clear.

Hypothetical measures of energy-use and energy-intensity (reciprocal of efficiency) indexes are shown in Table 4.5 for two appliances--refrigerators and furnaces. The figures in rows (3) and (6) represent the amount of energy needed to produce the same levels of energy services as in 1973. Total energy required to maintain the 1973 bundle of services is shown in row (7). The aggregate index of energy intensity (or efficiency, if the reciprocals of these values are used) is constructed by simply basing the hypothetical energy-use series to $1973=1.0$. Thus, it is clear that the estimates of total energy consumption are simply used as weights that are applied to the intensity (or efficiency) indexes for the individual appliances.

Unfortunately, actual 1973 estimates of energy use by appliance type were not available since the base year at ORNL model used was 1977. Accordingly, 1977 energy use estimates for the model were used (as shown in the first column of Table 4.4). However, since it is relative energy consumption levels that actually enter into the calculation of the aggregate index, this step should introduce a second order error, at most. After the aggregate index was constructed with the 1977 base year, it was then renormalized to 1973 . 
TABLE 4.5. Illustration of Construction of Aggregate Efficiency Index

Appliance $\quad \underline{1973} \quad \underline{1975} \quad \underline{1980}$

Refrigerators

$\begin{array}{llrr}\text { (1) Actua 1 Energy Use (Quads) } & 1.20 & -- & -- \\ \text { (2) Intensity Index } & 1.00 & .95 & .90 \\ \text { (3) Computed Energy Use (Quads) } & 1.20 & 1.14 & 1.08\end{array}$

Gas Furnaces

(4) Actual Energy Use (Quads)

2.6

1.00

$\begin{array}{llll}\text { (6) Computed Energy Use (Quads) } & 2.6 & 2.55 & 2.50\end{array}$

$2 . \overline{98}$

.96

Aggregate

(7) Computed Energy Use

$$
(3)+(6), \text { Quads }
$$

(8) Index of (7) (1973 base)

The appliance types for which efficiency information was available (in Table 4.4) accounted for about 80 percent of total energy consumption in 1977. In making the aggregate index, it was assumed that there was no efficiency improvement in these other types of equipment.

The final results of these calculations are shown in Table 4.6. As mentioned earlier, we assumed no efficiency improvements until 1985; thus, the 1973, 1974, and 1975 indexes are all identically equal to 1.0. In addition to the aggregate index, three subindexes were computed for (1) heating and cooling equipment, (2) refrigerators and freezers, and (3) other appliances. Because of the relatively greater efficiency improvement in new refrigerators and freezers (compared to 1972), the improvement in efficiency of the stock of this equipment is estimated to be more than 5 percent higher than is the base year. The efficiency of the stock of space conditioning equipment is estimated to have increased less than 1 percent over the same interval. 
TABLE 4.6. Equipment Stock Energy Intensity Indexes

$\begin{array}{lccccc} & \text { Aggregate } & \begin{array}{c}\text { Space } \\ \text { Conditioning }\end{array} & \begin{array}{c}\text { Refrigerators } \\ \text { and Freezes }\end{array} & & \text { 0ther } \\ 1973 & 1.0 & 1.0 & & 1.0 & 1.0 \\ 1976 & .999 & .999 & .996 & .999 \\ 1977 & .997 & .999 & .999 & .997 \\ 1978 & .995 & .998 & .997 & .994 \\ 1979 & .991 & .996 & .964 & .991 \\ 1980 & .987 & .994 & .949 & .987\end{array}$

\subsection{SIZE OF DWELLING UNIT}

The purpose of this task was to estimate the impact of changing sizes of dwellings on residential energy use. A measure, therefore, of the average size of the housing stock must be developed.

The National Interim Energy Consumption Survey (NIECS) provided the on ly available source for estimates of the square footage of the dwelling unit stock. This survey was administered in 1978, so estimates for 1979 and 1980 stock were unavailable.

By stratifying the sample by the year the dwelling unit was built, estimates for the average size of the stock were constructed for the years 19741978. Table 4.7 presents these results. Implicit in this approach are several assumptions: (1) that NIECS is a representative sample of dwelling units, (2) that the square footage figures reported are accurate, and (3) that any retirements which occurred between 1974 and 1978 would not bias the estimates across time periods.

TABLE 4.7. Average Dwelling Unit Size, 1974-1978

$\begin{array}{ccc}\text { Year } & \text { Mean } & \text { Standard Error } \\ 1974 & 1445 & 912 \\ 1975 & 1443 & 907 \\ 1976 & 1447 & 901 \\ 1977 & 1455 & 901 \\ 1978 & 1451 & 895\end{array}$


As revealed in the above table, there is no statistically significant change in the size of dwelling units over the study period. Furthermore, there is no strong evidence of any sort of apparent trend, as the mean size of the stock declines in 1975, then rises for two consecutive years, then falls again in 1978. There may be problems with assuming that NIECS is a representative sample of dwelling units; however, the sheer size of the stock would tend to dampen the effect of changes in the size of additions over the study period.

Due to the lack of any apparent trend in the size of stock, and the lack of an alternate data source, this effect was judged to be insignificant and was excluded from further research.

\subsection{FUEL SWITCHING}

Fuel switching on the part of a household can result in energy savings in two different ways. A savings in primary energy use can occur when, in making the switch, a household converts from a less efficient to a more efficient end use technology, for example, from electric space heating to gas space heating. A savings in nonrenewable forms of energy occurs when, for a given end use, a household switches from a nonrenewable to a renewable energy using technology, for example, from gas or electric space heating to a wood-fueled system.

Of the two forms of fuel switching, the second type is of greatest interest to policy makers. Fragmentary evidence suggests that fuel switching from nonrenewable space heating units to wood-fired units has been fairly extensive in some parts of the U.S., notably in the Northwest and Northeast. However, no consistent data series currently exists which would make it possible to examine the magnitude of even this single type of shift on a national basis. Therefore, no estimate of the average energy saving per household due to switching from nonrenewable to renewable forms of energy is included in this report. 


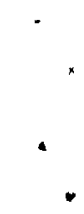




\section{REFERENCES}

Adams, R. C., and A. D. Rockwood. 1981. Impact of Improved Building Thermal Efficiency on Residential Energy Demand. PNL-3733 Pacific Northwest Laboratory, Richland, Washington.

Hartman, R. S., and A. Werth. 1979. Short-Run Residential Demand for Fuels: A Disaggregated Approach. MIT Energy Laboratory Working Paper No. MIT-EL-79-018, Massachusetts Institute of Technology, Cambridge, Massachusetts.

U. S. Department of Commerce Bureau of the Census. 1973-1980. Statistical Abstract of the United States, U. S. Government Printing Office, Washington, D.C. 


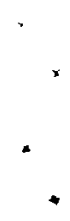




\section{DISTRIBUTION}

No. of

Copies

$\underline{\text { OFFSITE }}$

5

Alisa Gravitz

Office of Policy, Planning and Analysis

Department of Energy

Forrestal Building, Mail Stop PE-34

1000 Independence Avenue, S.W.

Washington, D.C. 20585

5

Bill White

Office of Policy Planning and Analysis

Department of Energy

Forrestal Building, Mail Stop PE-35

1000 Independence Avenue, S.W.

Washington, D.C. 20585

Eric Hirst

Oak Ridge National Laboratory

P.0. Box $X$

Oak Ridge, Tennessee 37830

27

DOE Technical Information Center

ONSITE

DOE Richland Operations Office

$$
\text { HE Ransom }
$$

Pacific Northwest Laboratory

MJ King (5)

RC Adams (5)

$\mathrm{OB}$ Belzer (5)

JM Callaway

JW Currie

S. Liebetrau

Technical Information (5)

Publishing Coordination KE (2) 


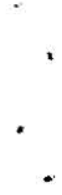

